\title{
Early-stage clear cell tubulopapillary renal cell carcinoma: imaging features and distinction from clear cell and papillary subtypes
}

\section{Citation}

Mnatzakanian, Gevork N., Atul B. Shinagare, V. Anik Sahni, Michelle S. Hirsch, and Stuart G. Silverman. 2016. “Early-Stage Clear Cell Tubulopapillary Renal Cell Carcinoma: Imaging Features and Distinction from Clear Cell and Papillary Subtypes." Abdominal Radiology 41 (11) (July 6): 2187-2195. doi:10.1007/s00261-016-0830-8.

\section{Published Version}

doi:10.1007/s00261-016-0830-8

\section{Permanent link}

http://nrs.harvard.edu/urn-3:HUL.InstRepos:32659588

\section{Terms of Use}

This article was downloaded from Harvard University's DASH repository, and is made available under the terms and conditions applicable to Other Posted Material, as set forth at http:// nrs.harvard.edu/urn-3:HUL.InstRepos:dash.current.terms-of-use\#LAA

\section{Share Your Story}

The Harvard community has made this article openly available.

Please share how this access benefits you. Submit a story. 


\begin{abstract}
Purpose: Clear cell tubulopapillary renal cell carcinoma (CCTPRCC) is a recently described, low grade subtype of renal cancer. We determined if imaging features could be used to distinguish early-stage CCTPRCC from stage-matched clear cell RCC (ccRCC) and papillary $\mathrm{RCC}(\mathrm{pRCC})$.
\end{abstract}

Subjects and Methods: This IRB-approved retrospective study included 54 stage-Ia patients with pathologically-confirmed CCTPRCC $(n=18), \operatorname{ccRCC}(n=18)$, and pRCC $(n=18)$. CT $(n=48)$ and MRI ( $\mathrm{n}=27)$ exams were reviewed and imaging features compared. Continuous variables were evaluated using ANOVA and Tukey's multiple comparison tests. Categorical variables were compared using Chi square test or Fisher's exact test.

Results: Compared to pRCC, CCTPRCC had a lower mean attenuation value on unenhanced CT $(p<0.017)$, was more often hyperintense on T2-weighted images $(p<0.0001)$, showed an illdefined margin $(p=0.003)$, and demonstrated nonenhancing areas $(p=0.0003)$. The presence of all three of these statistically significant features (hypoattenuation [unenhanced attenuation $\leq$ 25HU], ill-defined margin, nonenhancing areas) yielded an area under the Receiver Operator Curve (ROC) of 0.92 (95\% CI: 0.83-0.99) for differentiating CCTPRCC from pRCC. There were no significant differences in the imaging features of CCTPRCC and ccRCC.

Conclusions: Early stage clear cell tubulopapillary renal cell carcinoma can be distinguished from papillary RCC based on low attenuation on unenhanced CT, high intensity on T2-weighted images, an ill-defined margin, and presence of nonenhancing areas, but cannot be distinguished from clear cell RCC. 


\section{INTRODUCTION}

Clear cell tubulopapillary renal cell carcinoma (CCTPRCC) represents a unique subtype of renal epithelial neoplasm according to the recent International Society of Urological Pathology Vancouver Classification of Renal Neoplasia [1,2]. Also known as 'clear cell papillary renal cell carcinoma' and previously referred to as 'papillary renal cell carcinoma with clear cell features', CCTPRCC is now considered the fourth most common variant of RCC, behind ccRCC (70\%), pRCC (16.6\%), and chromophobe carcinoma (5.9\%), with an incidence of 4.1\% [1-6].

CCTPRCC was reported initially in patients with end-stage renal disease, however, the majority of subsequent cases are now known to occur sporadically [1-3, 5-9]. The average age at presentation is 60 and there is no sex predilection $[1,2,8,9]$.

There is limited literature on the biologic behavior of CCTPRCC, however, prior reports suggest that these neoplasms behave indolently, and carry a favorable prognosis $[1-4,7-10]$. To our knowledge, metastases have not been reported [1-4, 7-11]. Therefore, the prospective differentiation of CCTPRCC from the more common subtypes such as clear cell RCC (ccRCC) and papillary RCC (pRCC) at an early stage may be useful for counseling patients on prognosis and treatment plans. For example, an active surveillance approach may be considered in a patient with CCTPRCC [12].

To our knowledge, no prior study has attempted to differentiate CCTPRCC from other renal cell tumor subtypes using imaging features. In a recent study of papillary renal cell carcinoma subtypes on CT and MRI, CCTPRCC was included as an 'atypical papillary RCC' and was not evaluated as a separate entity [13]. We determined if imaging features could be used to distinguish early-stage CCTPRCC from stage-matched ccRCC and pRCC. 


\title{
SUBJECTS AND METHODS
}

\author{
Subjects
}

This Health Insurance Portability and Accountability Act-compliant retrospective study was performed after approval of our institutional review board; informed consent was waived. Our pathology database revealed 23 patients with stage Ia CCTPRCC diagnosed at our institution; of these, 20 had a pre-treatment CT scan and/or an MRI examination available for review. Of these 20 patients, two had more than one subtype of RCC (including CCTPRCC) in the same surgical specimen. Therefore, we could not differentiate the two renal cell subtypes on imaging and were excluded. Thus, a total of 18 patients ( 9 men, 9 women; median age 65 years; range $43-84$ ) with stage Ia CCTPRCC were included in the study. Of these, 11 were examined with both CT and MRI, six with only CT, and one with only MRI. An equivalent number of consecutive stage matched $\operatorname{ccRCC}(\mathrm{N}=18 ; 12$ men, six women; median age 56 years; range 22-76) and an equivalent number of consecutive stage - matched $\mathrm{pRCC}(\mathrm{N}=18 ; 10$ men, eight women; median age 64 years; range 50-80) were identified and included to comprise a total of 54 patients in the study.

\section{CT and MRI Technique}

Of the 54 patients, 27 were examined with CT alone, 21 with both $\mathrm{CT}$ and MRI, and six with MRI alone. CT examinations were performed with MDCT scanners (Somatom Volume Zoom, Definition AS 128, Somatom Sensation 64 and 16, all from Siemens Medical Solutions, Erlangen, Germany); or Aquilion 320 and Aquilion 64, both from Toshiba (America Medical Systems, Minnetonka, MN). Images were acquired at $120 \mathrm{kVp}$ and $155-280 \mathrm{~mA}$, and reconstructed at 3- to 5-mm-thick sections in the axial plane and 3-mm thick sections in the 
coronal plane. Contrast-enhanced CT images were obtained after intravenous injection of 75-120 $\mathrm{mL}$ of iopromide (Ultravist 300, Bayer Healthcare, Seattle, WA). Thirty two patients underwent CT urography, supplemented with the injection of $10 \mathrm{mg}$ of IV furosemide (Lasix, Abbott Laboratories) administered 2-3 minutes before contrast material, or supplemented with a drip infusion of $250 \mathrm{~mL}$ of IV saline just prior to obtaining the excretory phase images [14]. Nine patients' CT scans were performed with IV contrast material using a 70s delay without an unenhanced phase. Seven patients' CT scans were performed without IV or enteric contrast material administration as part of a CT-guided biopsy planning CT scan. These seven patients' CT scans were used to assess characteristics that could only be evaluated with unenhanced CT. MRI examinations were performed on a 1.5-T or 3-T system (Signa Excite 1.5T, GE Healthcare or Magnetom Verio 3T, Siemens Healthcare). Imaging included an axial fat suppressed T1weighted spoiled gradient-echo or a 3D fast-acquisition multiple excitation spoiled gradient-echo sequence before and after IV gadolinium administration. T2-weighted imaging was performed with a single-shot fast spin-echo sequence $(1,200-2,500 / 87-92$; number of echoes acquired per TR, 184-264; section thickness, $5 \mathrm{~mm}$; gap, $1 \mathrm{~mm}$; field of view, 32-40 cm) [15]. Respiratory triggered fat-suppressed single-shot echoplanar diffusion-weighted imaging was performed in the transverse plane with tri-directional diffusion gradients by using at least three $b$ values within the same acquisition. Of the 27 patients who were examined with MRI, two did not receive IV contrast material due to impaired renal function.

\section{Assessment of Imaging Features on Both CT and MRI}

Index CT and MRI exams were assessed independently by three abdominal radiologists with five, nine, and 12-years of experience; each was blinded to the pathologic subtype, clinical 
information, and the scores of the other readers. Discrepancies were resolved in consensus. The following imaging features were recorded for all tumors: maximal tumor diameter $(\mathrm{mm})$, tumor location (upper pole, mid kidney, or lower pole), growth pattern (endophytic, $<50 \%$ exophytic or $\geq 50 \%$ exophytic), tumor margin (well-defined or ill-defined), tumor composition (solid or cystic), appearance on unenhanced, nephrographic, and excretory phase $\mathrm{CT}$, attenuation values (HU) on all three phases, signal intensity on T1 (hypo-, iso-, hyperintense to renal parenchyma), T2 appearance (hypo-, iso-, hyperintense to renal parenchyma), appearance on diffusion weighted images (hypo-, iso-, hyperintense to renal parenchyma), as well as the presence or absence of calcification, central scar, capsule, nonenhancing areas, lesional fat, and lesional hemosiderin.

Maximum tumor diameter was defined as the maximum dimension in the axial plane on nephrographic or excretory phase images [16]. For growth pattern, a tumor was defined as endophytic if the tumor was located completely within the renal parenchyma with no bulge of the capsule [13]. A tumor was considered exophytic if a portion of its margin extended beyond the edge of the renal parenchyma [13]. A tumor margin was considered to be well-defined if $>90 \%$ of the entire tumor circumference was 'pencil-thin' sharp using a narrow window setting [16]. When both nephrographic and excretory phases were available and there was discordance between the two, the phase that showed the most well-defined tumor was used. Regarding tumor composition, a tumor was considered to be cystic when $\geq 50 \%$ of tumor volume was cystic, defined as fluid attenuation values $(\leq 20 \mathrm{HU})$. Tumors with $<50 \%$ cystic component were considered to be solid [16].

Regions of interest attenuation values were obtained on enhanced CT scans in the portion of the renal mass that revealed the most enhancement as determined subjectively on the axial images. 
Similar sized regions of interest attenuation values were obtained on the unenhanced CT scans corresponding to the same area of maximal enhancement. Enhancement was calculated by subtracting the high-attenuation values of the tumor on unenhanced images from the attenuation value on each of the following phases: nephrographic and excretory. The maximum degree of enhancement was recorded. An increase in attenuation of $20 \mathrm{HU}$ or greater indicated enhancement, an increase of 10-19 HU was considered equivocal, and an increase of less than 10 HU indicated no enhancement [13, 17-19]. For tumors imaged with MRI, the relative signal intensity in comparison to the normal renal parenchyma (e.g., hypointense, isointense, hyperintense) was assessed on unenhanced T1, T2, DWI, and contrast-enhanced T1-weighted images. The presence or absence of enhancement was determined subjectively on subtraction images.

Presence of calcification was assessed only with CT. The presence of a central scar was defined as a central stellate area of $\mathrm{T} 2$ hyperintensity with lack of enhancement during the nephrographic phase with or without enhancement during subsequent phases [20]. Nonenhancing areas (assessed for only solid tumors) were defined as hypoattenuating, nonenhancing areas which were not sharply demarcated and lacked apparent walls. Presence of lesional fat was defined as a region within the tumor that measured $-10 \mathrm{HU}$ or less on $\mathrm{CT}$, or exhibited a loss of signal on fatsaturated T1 images. Presence of intracytoplasmic fat was defined as loss of signal on T1 in- and out-of-phase imaging. Presence or absence of hemosiderin was only considered for tumors imaged with MRI and defined as the subjective identification of loss of signal intensity on longer-TE in-phase images relative to opposed-phase T1-weighted dual-echo gradient-recalled echo images [13]. 


\section{Statistical Analysis}

Stratified analyses of the three subtypes of RCC were conducted. Categorical variables were compared using Chi square test (gender, side, tumor location, Fuhrman grade, tumor growth pattern, capsule, nonenhancing areas, intralesional fat, central scar, presence of hemosiderin, MRI enhancement, T1, T2, and DWI signal intensities) and Fisher's exact test (tumor margin, tumor composition, presence of calcification, nephrographic phase appearance, homogeneity/heterogeneity on T1, T2, and DWI). Continuous variables were evaluated using ANOVA and Tukey's multiple comparison tests (age, tumor size, mean attenuation on unenhanced, nephrographic, and excretory phase). Further pairwise analyses were performed for statistically significant differences. Since three pair-wise analyses were performed, using Bonferroni correction, a statistically significant value was determined to $b e \leq 0.017$.

Then, the imaging features which were significantly different between the three cancer subtypes were used to construct a receiver operator curve (ROC) to determine the ability of these features to be used to differentiate them. The sensitivity and specificity for differentiating them when one or more of the features were present were calculated also. For this analysis, we assessed the unenhanced $\mathrm{CT}$ attenuation value as a binary variable (whether or not the mass was hypoattenuating) and performed a threshold analysis using $5 \mathrm{HU}$ increments starting at $20 \mathrm{HU}$, and used the lowest attenuation value that yielded a statistically significant difference between the three cancer subtypes. The number of patients did not allow a multivariate analysis to be performed. The number of patients also did not allow assessment of signal intensity on T2weighted images to be included in the ROC analysis. Statistical analyses were performed using JMP Pro 11.0.0 (SAS Institute Inc, Cary, NC) and Prism 6 version 6.05 (GraphPad Software Inc, La Jolla, CA). 


\section{RESULTS}

CCTPRCC demonstrated a lower mean attenuation value on unenhanced CT than pRCC (24.9 HU versus $33.7 \mathrm{HU} ; \mathrm{p}<0.017$ ). (Fig. 1). However, the mean attenuation value of CCTPRCC (24.9 HU) was not different from that of $\operatorname{ccRCC}(25.9 \mathrm{HU})(\mathrm{p}>0.05)$ (Table 1). More CCTPRCCs were T2-hyperintense than pRCC $(p<0.0001)$; similarly more ccRCCs were T2hyperintense than pRCC $(p<0.002)$ (Fig. 2). However, there was no difference in number of T2hyperintense CCTPRCCs and ccRCCs $(p=0.330)$. More CCTPRCCs had an ill-defined margin than $\mathrm{pRCC}$ ( $p=0.003$ ), however, there was no significant difference when compared to ccRCC ( $p=0.733$ ) (Fig. 3). Of the 54 tumors, 47 were solid. Among these, both CCTPRCC and ccRCC more frequently demonstrated nonenhancing areas than $\mathrm{pRCC}(p=0.0003$ and 0.0006 respectively) (Fig. 4), but there was no difference in the frequency of nonenhancing areas between CCTPRCC and ccRCC $(p=0.990)$.

Several imaging features trended towards statistical significance, but pair-wise analyses did not reveal a statistical significant difference (Table 1). These included appearance of the tumor on nephrographic phase (homogeneous vs heterogeneous, $p=0.033$ ), appearance on the T1 unenhanced sequences (homogeneous vs heterogeneous, $p=0.045$ ), appearance on the T2 sequences (homogeneous vs heterogeneous, $p=0.045$ ), and appearance on the DWI sequences (homogeneous vs heterogeneous, $p=0.007)$. There were no significant differences $(p>0.05$ ) between CCTPRCC and the other subtypes for the remaining imaging features (Table 1).

The threshold analysis for attenuation values performed for the purpose of ROC analysis yielded a statistically significant unenhanced attenuation value of $\leq 25 \mathrm{HU}$ to differentiate between CCTPRCC and pRCC $(p=0.03)$. An ROC analysis of those features which were significant 
among the three cancer subtypes demonstrated that the presence of an attenuation value $\leq 25 \mathrm{HU}$, an ill-defined margin, and the presence of nonenhancing areas could help differentiate CCTPRCC from pRCC with an area under the curve of 0.92 (95\% CI: 0.83-0.99). When at least one of these features was present, the sensitivity and specificity for diagnosing CCTPRCC was 0.94 and 0.82 respectively. If at least two statistically significant features were present, the sensitivity and specificity for diagnosing CCTPRCC was 0.47 and 1.0, respectively.

\section{DISCUSSION}

With the burgeoning role of active surveillance in the management of renal cancer, there is a growing need for ways to help select which patients need prompt treatment and which do not $[12,21]$. One way to help select patients for active surveillance is to predict their tumors' biological behavior on the basis of histologic subtype. There are emerging data to suggest that RCC subtypes may be diagnosed with imaging [22, 23]; however, currently this distinction and the subsequent clinical management decision often rely on pathology obtained at biopsy.

CCTPRCC is a recently recognized subtype of renal cell carcinoma $[1,2]$ that has gross morphologic and histologic features which overlap with both ccRCC and pRCC [1-9, 11]. In the radiology literature, CCTPRCC has been considered among atypical pRCC subtypes [13], and to our knowledge, the imaging features of this recently described RCC subtype have not been described. Almost all (>95\%) of CCTPRCCs are stage T1a and do not demonstrate local invasion $[1-9,11]$. There are no reported cases of metastases or disease-related deaths [1-11]. In one study, none of 12 patients with stage T1a or T1b CCTPRCC who were followed (mean 19 months) showed local disease progression or developed a metastasis [4]; a similar favorable outcome has recently been published in two larger series of CCTPRCC $[5,6]$. Therefore, relative 
to the more common clear cell and papillary subtypes, CCTPRCC is considered an indolent cancer and may be appropriate to observe rather than treat in selected patients $[4,11]$.

This study suggests that early stage CCTPRCC can be distinguished from pRCC based on a lower mean attenuation value on unenhanced CT, high signal on T2-weighted images, an illdefined margin, and more frequent nonenhancing areas. Specifically, a threshold unenhanced attenuation of $25 \mathrm{HU}$ was found to be statistically significant for differentiating CCTPRCC from pRCC. This corroborates earlier works which demonstrated that early stage pRCC is typically hyperattenuating on unenhanced CT $[13,15]$. In contrast, the relatively low attenuation appearance for CCTPRCC can be explained by its pathology: CCTPRCC can include cystic components of various sizes [1-3, 7-9]. In fact, in the first description of CCTPRCC, 33 (92\%) of 36 tumors included cystic components that often contained serosanguinous fluid or colloid-like secretions [1].

The cystic nature of most of these tumors also probably explains why CCPRCC were T2hyperintense. It is difficult to postulate why CCTPRCC would exhibit an ill-defined margin relative to $\mathrm{pRCC}$. Perhaps due to their hybrid nature, this feature may mimic ccRCC, which have been shown to demonstrate ill-defined margins on imaging $[16,17]$. The higher frequency of non-enhancing areas was another feature that could be used to distinguish CCTPRCC from pRCC. Indeed, 8 (57\%) of 14 solid CCTPRCC exhibited nonenhancing areas. This data is similar to Egbert et al. [13] who described nonenhancing areas in two of six patients with CCTPRCC. Although others have used non-enhancement in solid masses as an imaging surrogate for tumor necrosis $[16,17]$ CCTPRCC typically does not demonstrate necrosis at histologic evaluation $[2,3]$. The nonenhancing areas may represent focal fibrosis, colloid or glycogen in the cells, focal cystic change, or necrosis $[1-3,5]$. 
In practical terms, when encountering a small renal mass, our data allow radiologists to include CCTPRCC in the differential diagnosis of neoplastic etiologies, and to favor it along with ccRCC when a mass measures less than or equal to $25 \mathrm{HU}$, is T2-hyperintense, or exhibits illdefined margins, or nonenhancing areas. The presence of two of these features increases the specificity for differentiating between CCTPRCC and pRCC, but the increased specificity comes at the cost of lowering the sensitivity. The finding that CCTPRCC cannot be differentiated from ccRCC is supported by several pathology studies that have described CCTPRCC as a mimicker of ccRCC $[1-3,11]$. For example, pathologists may have difficulty distinguishing CCTPRCC from ccRCC with a low Fuhrman grade $[1,2,4]$, and rely on immunohistochemistry to render the correct diagnosis $[1-4,7-9,11,24]$.

This study had several limitations. The study was retrospective; however, the readers were blinded to each patient's pathologic diagnosis in order to minimize bias. Also, both CT and MRI were not available for all patients. However, all patients (except for seven patients whose CT included only an unenhanced phase) were examined using protocols that included integral components for renal mass imaging, image acquisitions before and after intravenous contrast material administration and reconstructions with $3-5 \mathrm{~mm}$ section thickness [12]. The number of patients was overall small because the tumor has been only recently described. To our knowledge, this study is the largest series of CCTPRCC in the radiological literature.

In summary, CCTPRCC is a relatively recently described entity that can be included in the differential diagnosis of renal neoplasms and can be distinguished from pRCC but not ccRCC. Therefore, since CCTPRCC and ccRCC typically behave differently, more work will be needed before management decisions such as active surveillance can be made on the basis of imaging features alone. Additional imaging research may be helpful; for example, IV contrast material 
dynamics which have been shown to distinguish other renal neoplasm subtypes [22, 23, 25-28] may help distinguish CCTPRCC from ccRCC. Nevertheless, the results of our analysis could serve as the foundation for additional studies on the use of imaging to differentiate the recently described CCTPRCC from other RCC subtypes. Finally, a radiology-pathology correlation study would help understand the pathologic correlates of the imaging features of these sub-types. 


\section{REFERENCES}

1. Srigley JR, Delahunt B, Eble JN, et al. The International Society of Urological Pathology

(ISUP) Vancouver Classification of Renal Neoplasia. Am J Surg Pathol 2013; 37(10):1469-89

2. Aydin H, Chen L, Cheng L, et al. Clear cell tubulopapillary renal cell carcinoma: a study of 36 distinctive low-grade epithelial tumors of the kidney. Am J Surg Pathol 2010; 34(11):1608-21

3. Montironi R, Mazzucchelli R, Scarpelli M, Lopez-Beltran A, Cheng L. Update on selected renal cell tumors with clear cell features. With emphasis on multilocular cystic clear cell renal cell carcinoma. Histol Histopathol 2013; 28(12):1555-66

4. Zhou H, Zheng S, Truong LD, Ro JY, Ayala AG, Shen SS. Clear cell papillary renal cell carcinoma is the fourth most common histologic type of renal cell carcinoma in 290 consecutive nephrectomies for renal cell carcinoma. Human Pathology 2014; 45:59-64

5. Aron M, Chang E, Herrera L et al. Clear cell-papillary renal cell carcinoma of the kidney not associated with end-stage renal disease: clinicopathologic correlation with expanded immunophenotypic and molecular characterization of a large cohort with emphasis on relationship with renal angiomyoadenomatous tumor. Am J Surg Pathol. 2015; 39:873-88

6. Deml KF, Schildhaus HU, Comperat E et al. Clear cell papillary renal cell carcinoma and renal angiomyoadenomatous tumor: two variants of a morphologic, immunohistochemical, and genetic distinct entity of renal cell carcinoma. Am J Surg Pathol. 2015; 39:889-901

7. Gobbo S, Eble JN, Grignon DJ, et al. Clear cell papillary renal cell carcinoma: a distinct histopathologic and molecular genetic entity. Am J Surg Pathol 2008; 32(8):1239-45 
8. Adam J, Couturier J, Molinié V, Vieillefond A, Sibony M. Clear-cell papillary renal cell carcinoma: 24 cases of a distinct low-grade renal tumour and a comparative genomic hybridization array study of seven cases. Histopathology 2011; 58(7):1064-71

9. Rohan SM, Xiao Y, Liang Y, et al. Clear-cell papillary renal cell carcinoma: molecular and immunohistochemical analysis with emphasis on the von Hippel-Lindau gene and hypoxiainducible factor pathway-related proteins. Mod Pathol Off J U S Can Acad Pathol Inc 2011; 24(9):1207-20

10. Tickoo SK, dePeralta-Venturina MN, Harik LR, et al. Spectrum of epithelial neoplasms in end-stage renal disease: an experience from 66 tumor-bearing kidneys with emphasis on histologic patterns distinct from those in sporadic adult renal neoplasia. Am J Surg Pathol 2006; 30(2):141-53

11. Liddell, H, Mare A, Hewood S, Bennett G, Chan HF. Clear cell papillary renal cell carcinoma: A potential mimic of conventional clear cell renal carcinoma on core biopsy. Case Rep Uro 2015; Epub 2015 Jan 29

12. Silverman SG, Israel GM, Trinh QD. Incompletely characterized incidental renal masses: emerging data support conservative management. Radiology 2015; 275(1):28-42

13. Egbert ND, Caoili EM, Cohan RH, et al. Differentiation of papillary renal cell carcinoma subtypes on CT and MRI. AJR 2013; 201(2):347-55

14. Silverman SG, Akbar SA, Mortele KJ, Tuncali K, Bhagwat JG, Seifter JL. Multi-detector row CT urography of normal urinary collecting system: furosemide versus saline as adjunct to contrast medium. Radiology 2006; 240(3):749-55 
15. Oliva MR, Glickman JN, Zou KH, et al. Renal cell carcinoma: $\mathrm{t} 1$ and t2 signal intensity characteristics of papillary and clear cell types correlated with pathology. AJR 2009; 192(6):1524-30

16. Shinagare AB, Vikram R, Jaffe C, et al. Radiogenomics of clear cell carcinoma: preliminary findings of The Cancer Genome Atlas-Renal Cell Carcinoma (TCGA-RCC) Imaging Research Group. Abdom Imaging 2015; Epub 2015 Mar 10

17. Israel GM, Silverman SG. The incidental renal mass. Radiol Clin North Am 2011; 49(2):369-83

18. Silverman SG, Israel GM, Herts BR, Richie JP. Management of the incidental renal mass. Radiology 2008; 249(1):16-31

19. Chung EP, Herts BR, Linnell G, et al. Analysis of changes in attenuation of proven renal cysts on different scanning phases of triphasic MDCT. AJR 2004; 182(2):405-10

20. Rosenkrantz AB, Hindman N, Fitzgerald EF, Niver BE, Melamed J, Babb JS. MRI features of renal oncocytoma and chromophobe renal cell carcinoma. AJR 2010;195:W421-W427

21. Sun M, Abdollah F, Bianchi M, et al. Treatment management of small renal masses in the 21st century: a paradigm shift. Ann Surg Oncol 2012; 19(7):2380-2387

22. Lee-Felker SA, Felker ER, Tan N, et al. Qualitative and quantitative MDCT features for differentiating clear cell renal cell carcinoma from other solid renal cortical masses. AJR 2014;203(5):W516-W524 
23. Young JR, Margolis D, Sauk S, Pantuck AJ, Savre J, Raman SS. Clear cell renal cell carcinoma: discrimination from other renal cell carcinoma subtypes and oncocytoma at multiphasic multidetector CT. Radiology 2013; 267(2):444-53

24. Williamson SR, Eble JN, Cheng L, Grignon DJ. Clear cell papillary renal cell carcinoma: differential diagnosis and extended immunohistochemical profile. Mod Pathol. 2013; 26:697-708

25. Ruppert-Kohlmayr AJ, Uggowitzer M, Meissnitzer T, Ruppert G. Differentiation of renal clear cell carcinoma and renal papillary carcinoma using quantitative $\mathrm{CT}$ enhancement parameters. AJR 2004; 183:1387-1391

26. Zhang J, Lefkowitz RA, Ishill NM, et al. Solid renal cortical tumors: differentiation with CT. Radiology 2007; 244:494-504

27. Sun M, Ngo L, Genega EM, et al. Renal cell carcinoma: dynamic contrast-enhanced MR imaging for differentiation of tumor subtypes-correlation with pathologic findings. Radiology 2009; 250(3):793-802

28. Bata P, Gyebnar J, Laszlo D, et al. Clear cell renal cell carcinoma and papillary renal cell carcinoma: differentiation of distinct histological types with multiphase CT. Diagn interv Radiol $2013 ; 19: 387-392$ 
TABLE

Table 1: Imaging features of 54 patients with early stage clear cell tubulopapillary

(CCTPRCC), clear cell (ccRCC) and papillary (pRCC) renal cell carcinoma

\begin{tabular}{|c|c|c|c|c|}
\hline Imaging Feature & CCTPRCC (\%) & $\operatorname{ccRCC}(\%)$ & pRCC (\%) & $p$ value \\
\hline Maximum diameter $(\mathrm{mm})$ & 24 & 27 & 25 & 0.465 \\
\hline $\begin{array}{ll}\text { Side } & \\
& \text { Right } \\
\text { Left }\end{array}$ & $\begin{array}{l}11 / 18(61) \\
7 / 18(39)\end{array}$ & $\begin{array}{l}11 / 18(61) \\
7 / 18(39)\end{array}$ & $\begin{array}{l}12 / 18(67) \\
6 / 18(33)\end{array}$ & 0.924 \\
\hline $\begin{array}{l}\text { Location } \\
\quad \text { Upper } \\
\text { Mid } \\
\text { Lower }\end{array}$ & $\begin{array}{l}5 / 18(28) \\
7 / 18(39) \\
6 / 18(33)\end{array}$ & $\begin{array}{l}9 / 18(50) \\
3 / 18(17) \\
6 / 18(33)\end{array}$ & $\begin{array}{l}5 / 18(28) \\
9 / 18(50) \\
4 / 18(22)\end{array}$ & 0.274 \\
\hline Exophytic & $16 / 18(89)$ & 17/18 (94) & $18 / 18(100)$ & 0.416 \\
\hline Ill-defined margin & $8 / 18(44)$ & $6 / 18(33)$ & $0 / 18(0)$ & $\mathbf{0 . 0 0 3}^{\mathrm{a}}$ \\
\hline Calcification & $3 / 18(17)$ & $0 / 18(0)$ & $0 / 18(0)$ & 0.054 \\
\hline Central scar & $0 / 18(0)$ & $0 / 18(0)$ & $0 / 18(0)$ & 1.000 \\
\hline Capsule present & $7 / 18(39)$ & $5 / 18(28)$ & $8 / 18(44)$ & 0.574 \\
\hline Solid & $14 / 18(78)$ & $15 / 18(83)$ & $18 / 18(100)$ & 0.118 \\
\hline Nonenhancing areas & $8 / 14(57)$ & $8 / 15(53)$ & $0 / 18(0)$ & $0.0003^{a}$ \\
\hline Fat present & $1 / 18(6)$ & $1 / 18(6)$ & $0 / 18(0)$ & 0.595 \\
\hline $\begin{array}{l}\text { Nephrographic phase } \\
\text { Homogeneous } \\
\text { Heterogeneous }\end{array}$ & $\begin{array}{l}2 / 18(11) \\
16 / 18(89)\end{array}$ & $\begin{array}{l}4 / 18(22) \\
14 / 18(78)\end{array}$ & $\begin{array}{l}8 / 18(50) \\
8 / 18(50)\end{array}$ & 0.033 \\
\hline $\begin{array}{l}\text { Mean unenhanced attenuation } \\
\text { (HU) }\end{array}$ & 24.9 & 25.9 & 33.7 & $0.017^{\mathrm{a}}$ \\
\hline $\begin{array}{l}\text { Mean nephrographic } \\
\text { attenuation (HU) }\end{array}$ & 94.8 & 88.6 & 67.9 & 0.639 \\
\hline $\begin{array}{l}\text { Mean excretory attenuation } \\
\text { (HU) }\end{array}$ & 66.6 & 60.7 & 55.6 & 0.317 \\
\hline Hemosiderin present & $0 / 12(0)$ & $0 / 6(0)$ & $0 / 9(0)$ & 1.000 \\
\hline & & & & \\
\hline
\end{tabular}




\begin{tabular}{|c|c|c|c|c|}
\hline $\begin{array}{c}\text { T1 unenhanced signal } \\
\text { Homogeneous } \\
\text { Heterogeneous }\end{array}$ & $\begin{array}{l}3 / 12(25) \\
9 / 12(75)\end{array}$ & $\begin{array}{l}2 / 6(33) \\
4 / 6(67)\end{array}$ & $\begin{array}{l}7 / 9(78) \\
2 / 9(22)\end{array}$ & 0.045 \\
\hline \multicolumn{5}{|l|}{ T1 unenhanced signal } \\
\hline Hypointense & $6 / 12(50)$ & $3 / 6(50)$ & $0 / 9(0)$ & \multirow{3}{*}{0.079} \\
\hline Isointense & $6 / 12(50)$ & $3 / 6(50)$ & 8/9 (89) & \\
\hline Hyperintense & $0 / 12(0)$ & $0 / 6(0)$ & $1 / 9(11)$ & \\
\hline \multicolumn{5}{|l|}{$\mathrm{T} 2$ signal } \\
\hline Homogeneous & $1 / 12(8)$ & $0 / 6(0)$ & 4/9 (44) & \multirow[t]{2}{*}{0.045} \\
\hline Heterogeneous & $11 / 12(92)$ & $6 / 6(100)$ & $5 / 9(56)$ & \\
\hline \multicolumn{5}{|l|}{$\mathrm{T} 2$ signal } \\
\hline Hypointense & $0 / 12(0)$ & $1 / 6(17)$ & 9/9 (100) & \multirow{3}{*}{$0.0001^{\mathrm{a}}$} \\
\hline Isointense & $1 / 12(8)$ & $0 / 6(0)$ & $0 / 9(0)$ & \\
\hline Hyperintense & $11 / 12(92)$ & $5 / 6(83)$ & $0 / 9(0)$ & \\
\hline \multicolumn{5}{|l|}{ DWI signal } \\
\hline Homogeneous & $0 / 4(0)$ & $0 / 4(0)$ & $2 / 2(100)$ & \multirow[t]{2}{*}{0.007} \\
\hline Heterogeneous & $4 / 4(100)$ & $4 / 4(100)$ & $0 / 2(0)$ & \\
\hline \multicolumn{5}{|l|}{ DWI signal } \\
\hline Hypointense & $0 / 4(0)$ & $1 / 4(25)$ & $0 / 2(0)$ & \multirow{3}{*}{0.435} \\
\hline Isointense & $0 / 4(0)$ & $0 / 4(0)$ & $0 / 2(0)$ & \\
\hline Hyperintense & $4 / 4(100)$ & $3 / 4(75)$ & $2 / 2(100)$ & \\
\hline Enhancement present on MRI & 11/11(100) & $6 / 6(100)$ & $8 / 8(100)$ & 1.000 \\
\hline
\end{tabular}




\section{FIGURES}
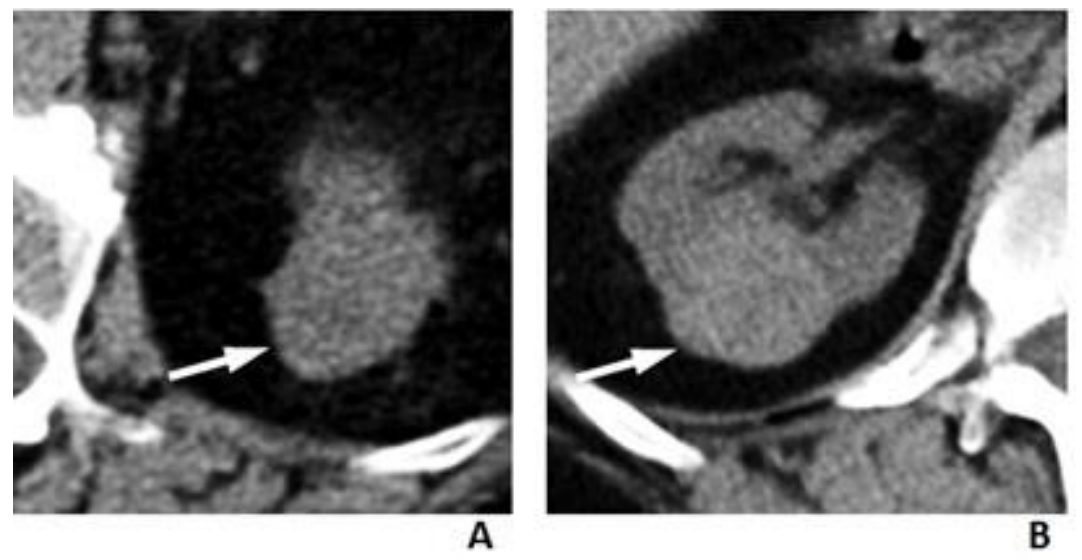

Fig. 1 - CCTPRCC (24.9 HU) demonstrated a lower mean unenhanced attenuation value than that of pRCC (33.7 $\mathrm{HU})(p<0.017)$. A, 84-year-old woman with CCTPRCC (14 HU). B, 61-year-old woman with pRCC (51 HU).
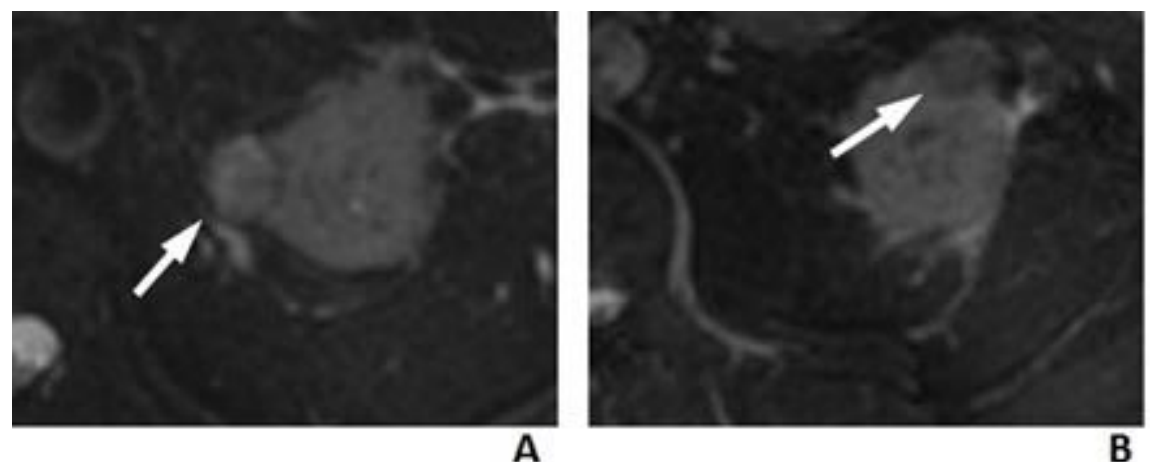

Fig. 2 - More CCTPRCCs were T2-hyperintense than pRCC ( $p<0.0001)$. A, 65-year-old man with CCTPRCC demonstrating heterogeneously hyperintense T2 signal. B, 52-year-old man with pRCC demonstrating homogeneously hypointense T2 signal. 

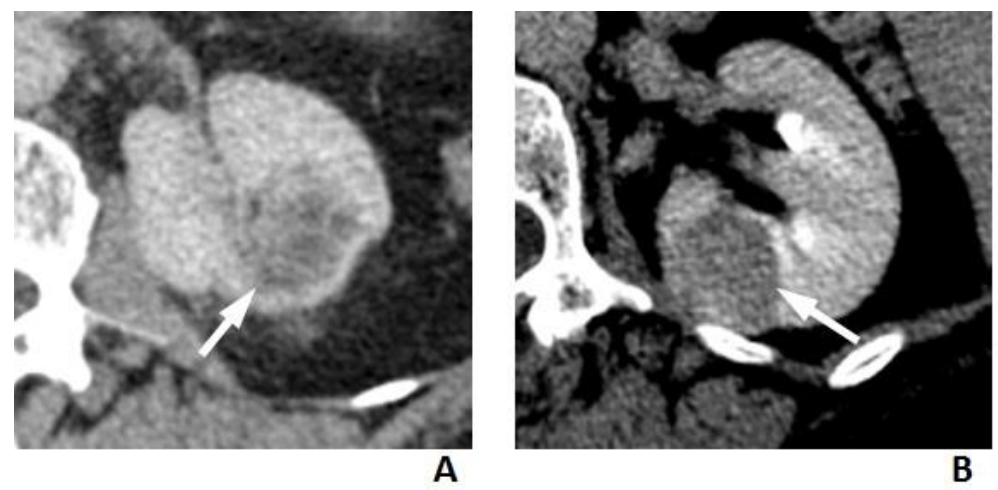

Fig. 3 - More CCTPRCCs had an ill-defined margin than pRCC ( $p=0.003)$. A, 75-year-old woman with CCTPRCC demonstrating an ill-defined tumor margin. B, 64-year-old man with pRCC demonstrating a well-defined tumor margin.
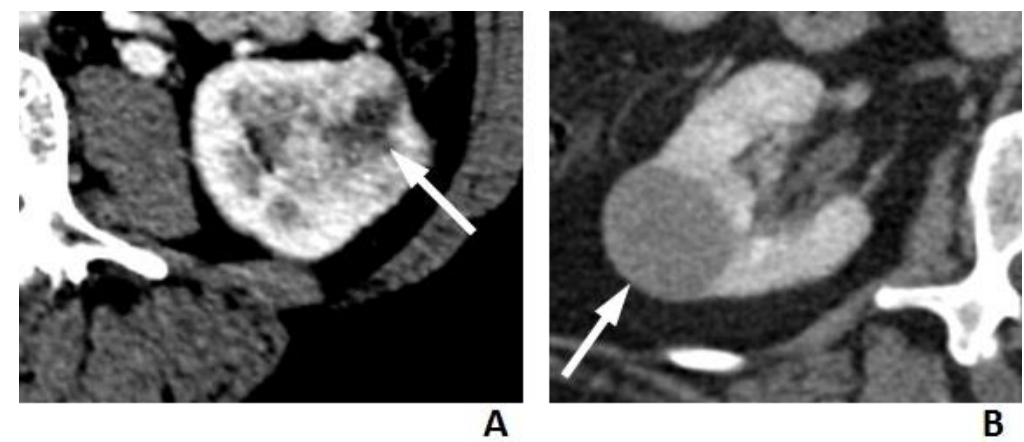

Fig. 4 - Among the tumors which were classified as solid, CCTPRCC more frequently demonstrated nonenhancing areas than $\mathrm{pRCC}(p=0.0003)$. A, 76-year-old man with CCTPRCC demonstrating an eccentric nonenhancing area within the tumor. B, 69-year-old woman with pRCC demonstrating no nonenhancing areas. 